\title{
Pemanfaatan Ekstrak Daun Sirih Hijau (Piper Betle L.) Sebagai Zat Pewarna Alami (ZPA) Tekstil Dan Aplikasinya pada Benang Tenun
}

\section{Muhamad Afan, Agrippina Wiraningtyas, Sry Agustina dan Ruslan}

\author{
Program Studi Pendidikan Kimia, STKIP Bima \\ Jl. Tendean, Mande, Kota Bima, NTB, 84019 Indonesia \\ Email: afanciwintarasembilanbintang15@gmail.com
}

\begin{abstract}
ABSTRAK
Penelitian ini bertujuan untuk memanfaatkan daun Sirih (Piper Betle L.) sebagai zat warna alam pada tekstil. Tahap pengolahan Pemanfaatan Ekstrak Warna Daun Sirih Hijau (Piper Betle L.) ZPA (Zat Pewarna Alami) Tekstil Pada Aplikasi Benang Tenun Bima dilakukan melalui beberapa tahapan diantaranya ekstraksi zat pewarna alam, mordanting, pewarnaan dan proses fiksasi. Hasil pewarnaan benang dapat dilihat perubahan warna yang dihasilkan, benang yang awalnya berwarna putih tetapi mengalami perubahan warna setelah direndam dalam zat warna ekstrak daun sirih hijau. Warna yang dihasilkan yaitu untuk variasi maserasi 1, 3, 4 dan 5 jam berwarna putih kecoklatan sedangkan untuk variasi maserasi 2 jam benang berwarna putih keemasan. Sedangkan dari hasil pengujian yang dilakukan pengaruh dari zat fiksator tawas menghasilkan warna seperti warna asli sebelum melalui proses fiksasi warna yang dihasilkan dalam penelitian ini secara indera penglihatan berwarna putih, pada zat fiksator tunjung menghasilkan warna kearah yang lebih gelap warna yang dihasilkan dalam penelitian ini secara indera penglihatan berwarna kuning keemasan sedangkan dengan fiksasi kapur tohor menghasilkan warna yang berseberangan dari warna asli dan warna yang dihasilkan adalah warna putih kecoklatan.
\end{abstract}

Kata kunci: Ekstraksi, Daun Sirih Hijau, Zat Pewarna Alam, benang tenun

\section{PENDAHULUAN}

Penggunaan zat warna sintetis dalam industri tekstil saat ini telah banyak digunakan karena harganya yang relatif lebih murah, memiliki warna yang bervariasi, dan memiliki ketahanan luntur yang lebih baik dibandingkan dengan zat pewarna alami (ElNagar, dkk. 2005). Namun, menghadapi abad ke-21 yang berorientasi lingkungan, belakangan ini masyarakat khawatir terhadap dampak lingkungan dari penggunaan zat warna sintetis. Hal tersebut dikarenakan dapat mengganggu kesehatan berupa ancaman kanker sehingga tidak ramah terhadap lingkungan. Kondisi demikian dapat dijadikan tuas untuk mengembalikan peranan zat pewarna alami (Sutara, 2009), karena pewarna alami merupakan salah satu pilihan yang menjanjikan untuk pengembangan dalam pewarnaan tekstil yang lebih ramah lingkungan (Uddin, 2015). Zat warna alami memiliki potensi pasar yang tinggi sebagai komoditas unggulan produk Indonesia memasuki pasar global. Pada industri tekstil, pewarnaan menjadi bagian penting dalam proses pembuatan kain (Ruslan, 2019)

Salah satu tanaman yang dapat dijadikan sebagai pewarna alami yaitu daun sirih. Daun sirih hijau atau daun sirih jawa mengandung pigmen alami (antosianin). Potensi antosianin tersebut sebagai zat warna bisa dimanfaatkan sebagai zat pewarna alami salah satunya sebagai pewarna benang tenunan (Andjalita, 2015). Zat pewarna alam sangat berpotensi untuk digunakan sebagai pewarna pada benang tenun (Wiraningtyas, et al., 2020). Senyawa antosianin yang terdapat dalam daun sirih hijau dapat dipisahkan dengan 
cara ekstraksi. Ekstraksi adalah suatu metode yang dapat mengeluarkan komponen tertentu dari zat padat atau zat cair dengan cara pelarutan.

Benang tenun dari serat kapas mempunyai daya serap tinggi, penyerapan benang tenun bima berguna dalam proses pewarnaan dengan cara dicelup. Pewarnaan pada benang tenun bima menggunakan pewarna alam dilakukan dengan proses pencelupan dan perendaman. Proses pembuatan pewarna alam dilakukan dengan cara direbus dan dapat pula dilakukan dengan cara lain yaitu diblender. Cara-cara tersebut memiliki fungsi dan tujuan yang sama yaitu untuk mengeluarkan kandungan warna pada bahan alami sehingga memberikan hasil warna yang maksimal. Proses direbus dipengaruhi oleh suhu panas air ketika diproses diatas api, sedangkan proses diblender tidak merubah suhu yaitu hanya menggunakan pelarut air biasa (Mi'raj, 2013).

Pada penelitian ini, daun sirih diekstraksi menggunakan metode maserasi. Metode maserasi dipilih karena pengerjaan dan peralatan yang cukup mudah dan sederhana dimana kebanyakan sediaan herbal terstandar diekstraksi dengan metode ini. Sehingga berdasarkan alasan tersebut diatas, maka dilakukan penelitian mengenai Pemanfaatan Ekstrak Warna Daun Sirih Hijau (Piper Betle L.) Sebagai ZPA (Zat Pewarna Alami) Tekstil Pada Aplikasi Benang Tenun dengan variasi waktu ekstraksi selama 1, 2, 3, 4, dan 5 jam.

\section{METODE}

Penelitian ini adalah penelitian kualitatif yang dilakukan secara eksperimen untuk mengetahui Pemanfaatan Ekstrak Warna Daun Sirih Hijau (Piper Betle L.) Sebagai ZPA (Zat Pewarna Alami) Tekstil Pada Aplikasi Benang Tenun dengan menggunakan metode maserasi.

\section{Alat dan Bahan Penelitian}

Adapun alat dan bahan yang digunakan dalam penelitian ini adalah sebagai berikut : Baskom, blender (penghalus), sendok, gelas ukur, labu ukur, pipet tetes, tabung reaksi, rak tabung reaksi, gunting, beker glass, corong, erlenmeyer, saringan, dan Spektrofotometer UV-Vis. Bahan-bahan yang digunakan : aquades, daun sirih hijau (Piper betle L. ), etanol $96 \%$, kertas saring, kertas label, benang tenun, kapur tohor, tawas, tunjung, dan soda abu.

\section{Proses Ekstraksi menggunakan metode maserasi}

Daun sirih segar dipotong-potong dengan ukuran kira-kira $1,5 \mathrm{~cm}$. Kemudian daun diblender sampai halus untuk mempermudah proses ekstraksi. Metode yang digunakan untuk mengekstrak daun sirih adalah metode maserasi. Pada metode ini menggunakan etanol $70 \%$. Sebanyak 10 gram daun sirih hijau dicuci bersih, kemudian ditiriskan dan dihaluskan dengan blender hingga menjadi serbuk. Serbuk daun sirih direndam dengan etanol $70 \%$ selama 15 menit. Kemudian ambil filtrat dengan penyaringan. Maserasi dilakukan dengan cara perendaman selama 15 menit. Kemudian dilakukan penyaringan dengan kertas saring untuk memisahkan filtrat dari ampas. Maserasi dilakukan dengan variasi waktu yang berbeda dari 1, 2, 3, 4, dan 5 jam, lakukan pengulangan sesuai variasi waktu tersebut dan filtrat yang diperoleh diukur absorbansinya.

\section{HASIL DAN PEMBAHASAN \\ Proses Mordanting}


Mordanting bertujuan untuk menghilangkan kanji yang ada pada benang tenun, agar pori-pori benang terbuka sehingga benang mudah menyerap larutan zat pewarna.Tahap mordanting bertujuan untuk mensterilkan benang dari unsur logam dan lemak, mengembangkan serat benang sehingga mudah diserap zat warna alam (Lestari, dkk., 2018). Benang yang digunakan adalah benang berwarna putih dengan massa masingmasing 2,5 gram untuk setiap variasi maserasi.

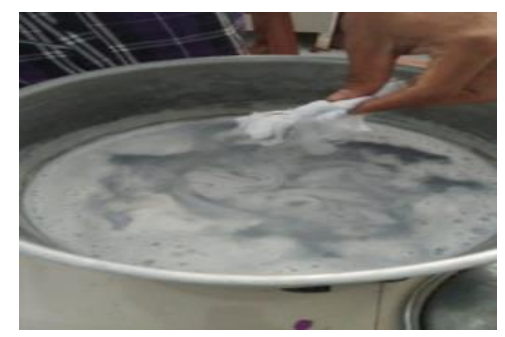

Gambar 1. Mordanting

\section{Ekstraksi Zat Pewarna Alam}

Proses pengolahan ekstraksi diblender dilakukan dengan memasukkan potongan daun sirih hijau kedalam. Setelah diblender dilakukan proses ekstraksi variasi waktu maserasi 1, 2, 3, 4, dan 5 jam. Setelah ekstrak tercampur dengan waktu maserasi yang ditentukan pelarut disaring menggunakan kertas saring. Penyaringan berupa residu dan filtrat, dimana residu dibuang dan filtrat diambil. Hasil ekstraksi inilah yang akan digunakan untuk proses pewarnaan benang.
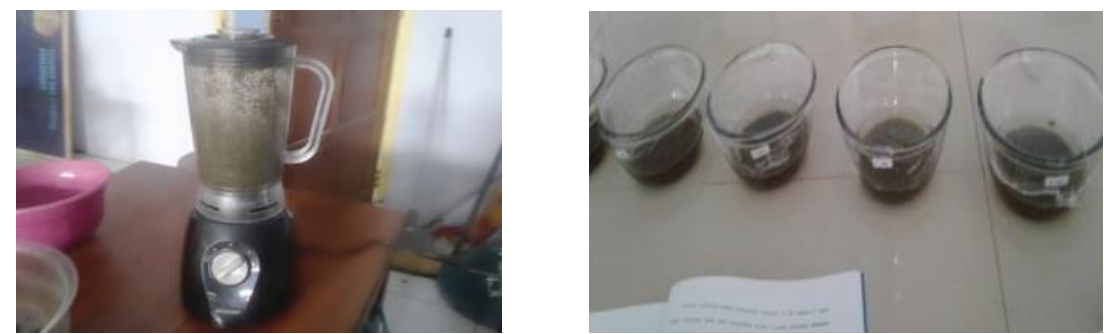

Gambar 2. Proses ekstraksi ZPA Daun Sirih Hijau

Hasil yang diperoleh dari proses ekstraksi dengan variasi waktu maserasi didapatkan dua data, yaitu data uji fisik dan data absorbansi. Pada data uji fisik didapatkan hasil berupa ekstrak berwarna orange, hijau pekat dan orange kecoklatan. Berikut warna secara fisik ekstrak zat warna dari daun sirih hijau pada variasi waktu maserasi 1, 2, 3, 4 dan 5 jam.

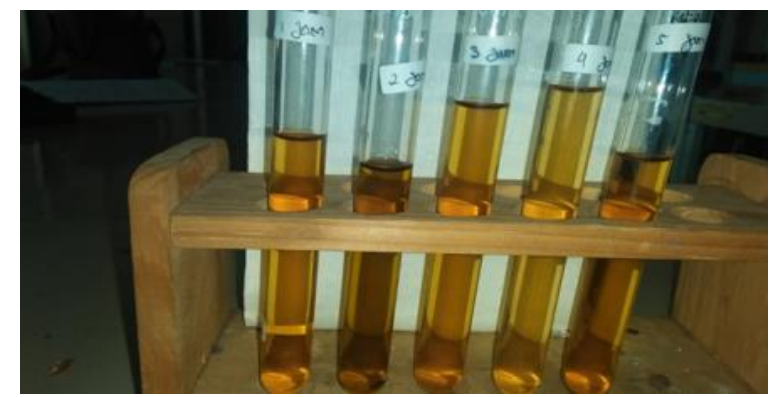

Gambar 3. Hasil ekstrak daun sirih hijau variasi waktu maserasi. 


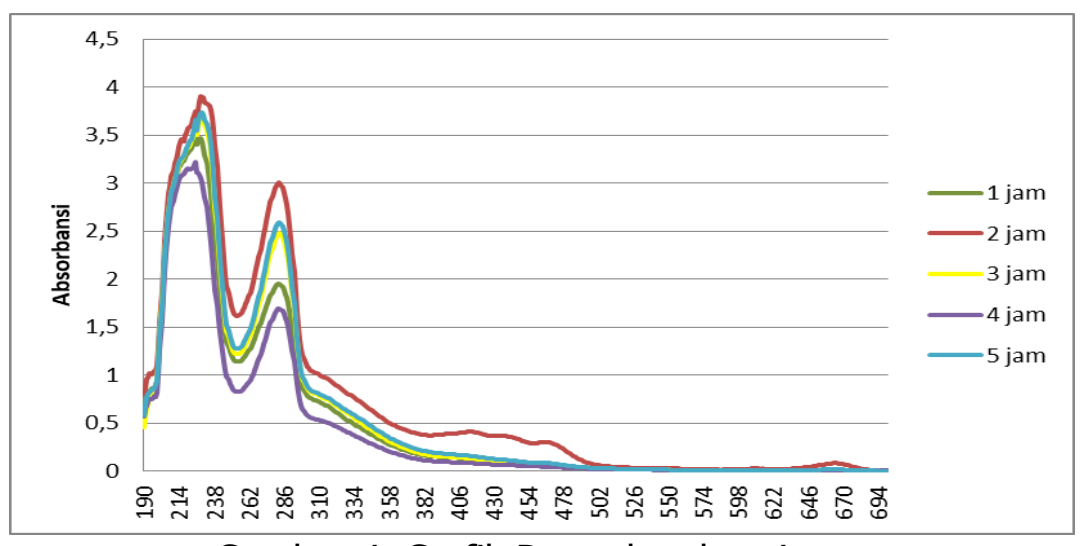

Gambar 4. Grafik Data absorbansi

Dari gambar diatas dapat dilihat bahwa semakin lama waktu maserasi ekstrak daun sirih hijau maka warnanya semakin baik. Terbukti pada maserasi variasi 2 jam nilai absorbansi tertinggi yaitu 3,907. Namun terjadi penurunan absorbansi pada maserasi variasi waktu 4 jam, dimana nilai absorbansi mengalami penurunan menjadi 3,220. Penurunan absorbansi ini disebabkan karena terjadi kerusakan gugus kromofor pigmen yang menyebabkan kerusakan warna. Semakin lamanya waktu maserasi maka akan mengakibatkan pigmen mengalami degradasi dan nilai absorbansinya menurun (Ruslan, 2020). Selama maserasi dapat terjadi degradasi dan perubahan struktur pigmen sehingga terjadi pemucatan. Kerusakan tersebut disebabkan oleh beberapa fakror seperti temperatur, cahaya, dan oksigen. Sehingga dalam penelitian ini absorbansi tertinggi pada maserasi variasi waktu 2 jam sedangkan penurunan absorbansi pada maserasi variasi waktu 4 jam.

\section{Pewarnaan Benang dengan Zat Warna Daun Sirih Hijau}

Pewarnaan bahan benang tenun dilakukan dengan cara direndam dengan filtrat ekstrak daun sirih hijau selama 15 menit pada variasi waktu 1, 2, 3, 4 dan 5 jam. Pewarnaan benang dengan cara direndam adalah proses pemberian warna pada bahan benang tenun. Tujuan dari proses perendaman ini agar terjadi penyerapan zat warna ke dalam benang (Azizah, 2018).

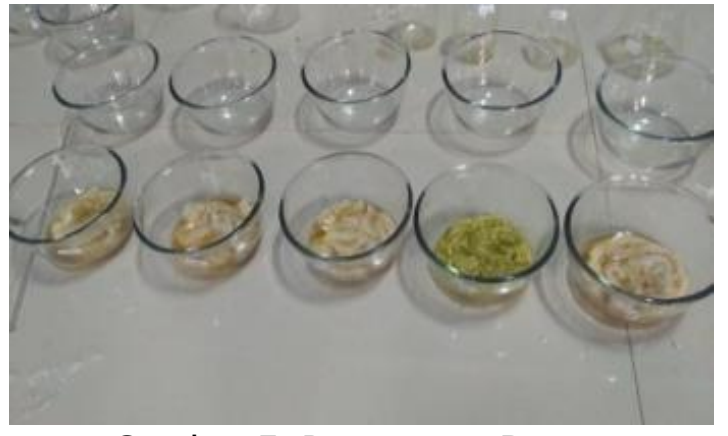

Gambar 5. Pewarnaan Benang 
Hasil pewarnaan benang dapat dilihat pada gambar 5. Perubahan warna yang dihasilkan, benang yang awalnya berwarna putih tetapi mengalami perubahan warna setelah direndam dalam zat warna ekstrak daun sirih hijau. Warna yang dihasilkan yaitu untuk variasi maserasi 1, 3, 4 dan 5 jam berwarna putih kecoklatan sedangkan untuk variasi maserasi 2 jam benang berwarna putih keemasan. Berikut warna secara fisik benang hasil pewarnaan menggunakan zat warna dari daun sirih hijau dengan variasi maserasi waktu 1, 2, 3, 4 dan 5 jam.

\section{Proses Fiksasi}

Proses fiksasi dilakukan dengan cara melarutkan bahan pada larutan yaitu berupa air. Takaran yang digunakan untuk melarutkan bahan sesuai dengan tabel bahan fiksasi. Pada proses akhir pewarnaan dengan zat warna alam dilakukan proses fiksasi. Tujuannya yaitu untuk penguncian warna, agar warna memiliki ketahanan luntur yang baik (Thomas, dkk., 2013). Proses fikasasi bertujuan untuk mengunci zat warna setelah melalui proses pencelupan.

Dari hasil pengujian yang dilakukan pengaruh dari zat fiksator tawas menghasilkan warna seperti warna asli sebelum melalui proses fiksasi warna yang dihasilkan dalam penelitian ini secara indera penglihatan berwarna putih, pada zat fiksator tunjung menghasilkan warna kearah yang lebih gelap warna yang dihasilkan dalam penelitian ini secara indera penglihatan berwarna kuning keemasan sedangkan dengan fiksasi kapur tohor menghasilkan warna yang berseberangan dari warna asli dan warna yang dihasilkan adalah warna putih kecoklatan. Seperti yang terlihat pada Tabel dibawah ini.

Tabel 1. Pengaruh larutan fiksasi pada hasil warna benang tenun

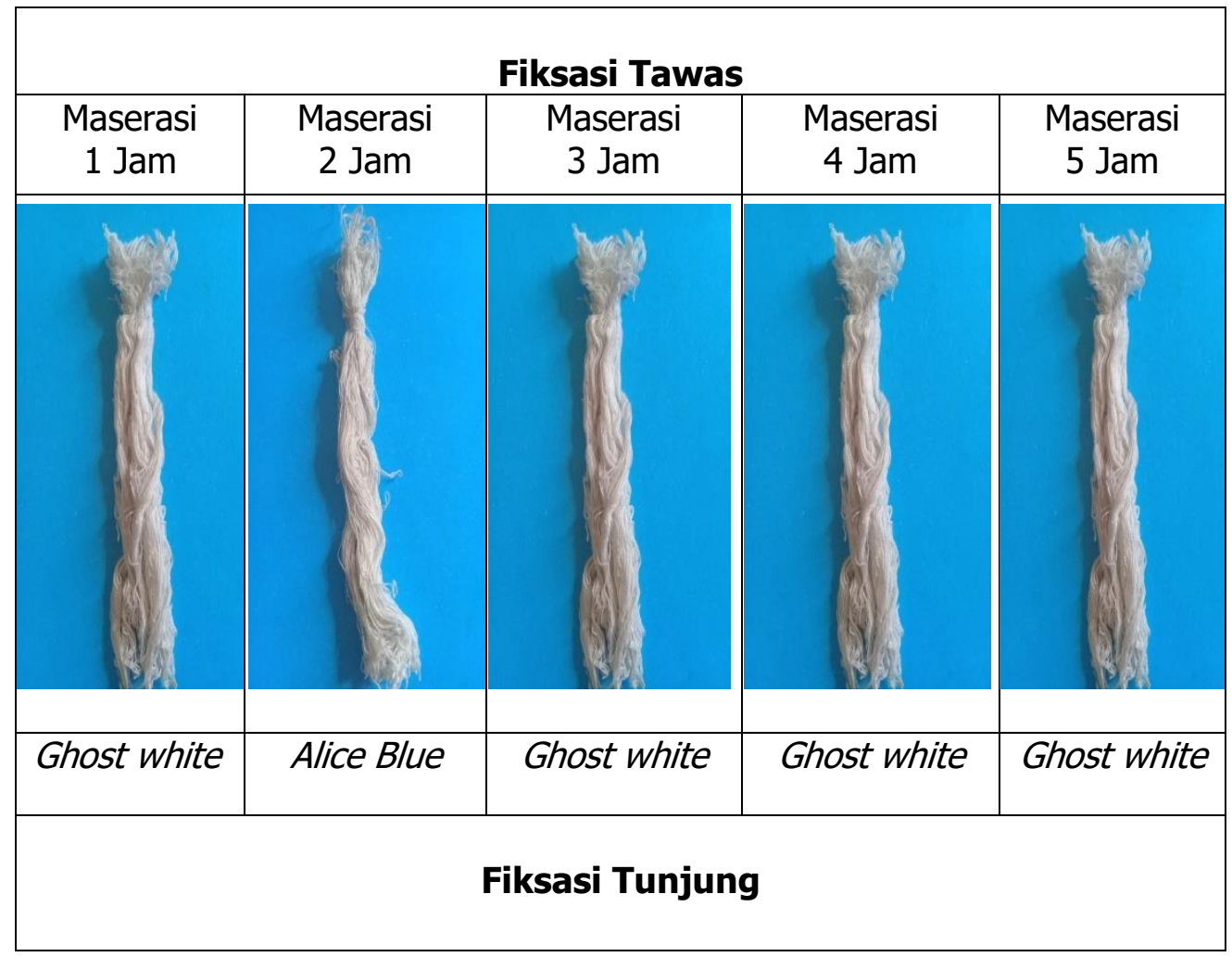




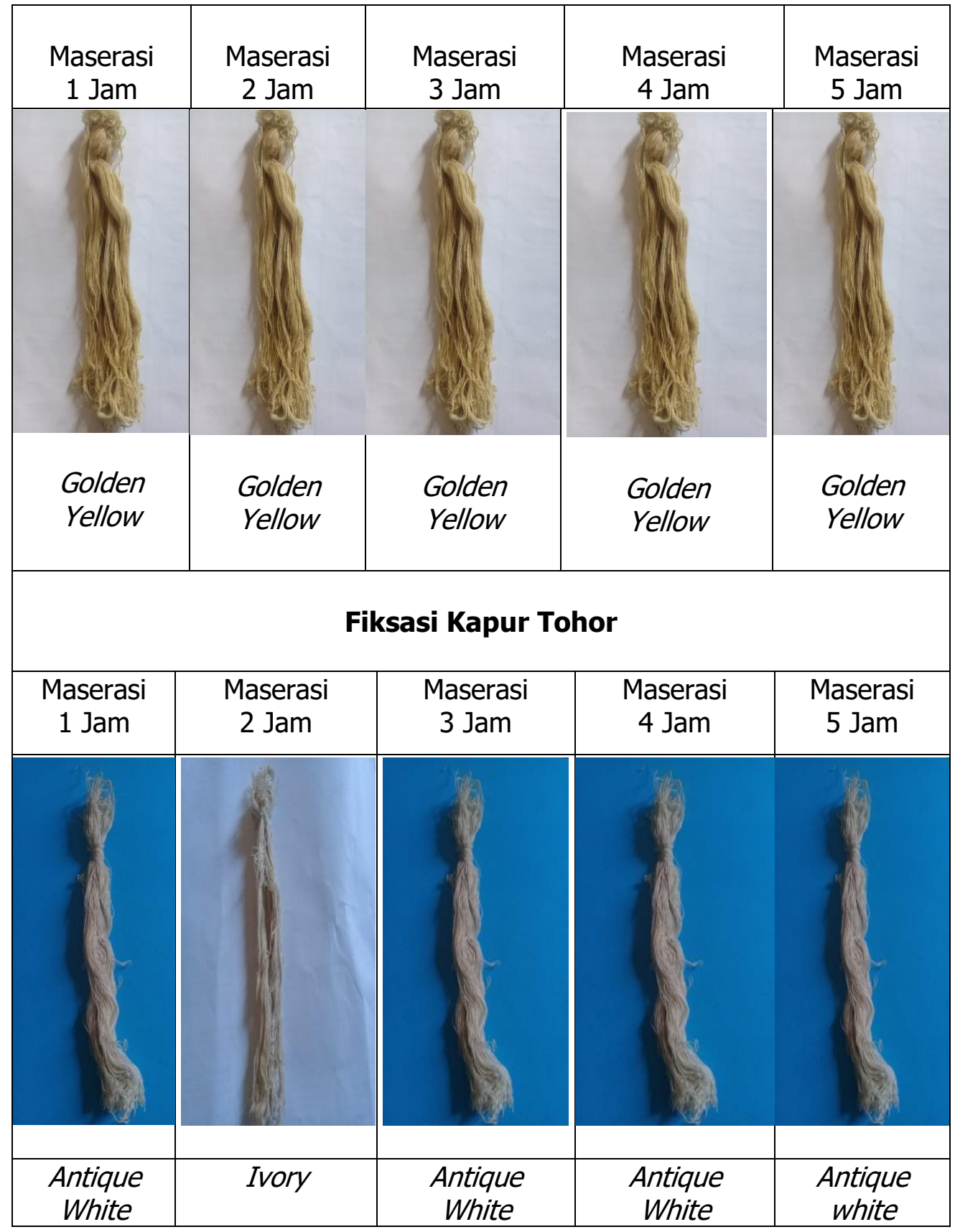

Berdasarkan tabel 1 dapat dilihat adanya perbedaan warna benang dari pewarnaan menggunakan ekstrak daun sirih hijau (Piper Betle L.) dengan berbagai variasi waktu maserasi. Warna awal benang sebelum difiksasi yaitu untuk variasi waktu 1, 3, 4 dan 5 jam adalah berwarna putih kecoklatan, sedangkan untuk variasi maserasi 2 jam benang berwarna kuning keemasan seperti yang terlihat pada tabel 1 . Namun setelah difiksasi menggunakan tawas terjadi perubahan warna pada benang variasi waktu maserasi 1, 3, 4 dan 5 jam menjadi warna Ghost white, sedangkan pada variasi maserasi 2 jam benang berwarna Alice Blue. Untuk benang yang menggunakan bahan fiksasi kapur variasi waktu maserasi 1, 3, 4 dan 5 jam menjadi warna Antique White, pada maserasi variasi waktu 2 jam benang berwarna Ivory. Sedangkan dengan fiksasi menggunakan tunjung warna benang pada variasi waktu maserasi 1, 2, 3, 4 dan 5 jam menjadi Golden Yellow. 
Perubahan warna yang terjadi pada benang dengan bahan fiksasi tawas dipengaruhi oleh senyawa kimia yang terdapat dalam tawas yaitu $\mathrm{Al}^{3+}$ yang bereaksi dengan ekstrak daun sirih hijau sedangkan untuk bahan fiksasi kapur dipengaruhi oleh kandungan senyawa yang terdapat dalam kapur yaitu $\mathrm{Ca}^{2+}$ yang bereaksi dengan ekstrak daun sirih hijau (Septiandini \& Muflihati, 2019). Kemudian yang menggunakan bahan fiksasi tunjung dengan variasi waktu pelarut maserasi 1, 2, 3, 4 dan 5 jam warna benang yang dihasilkan yaitu warna abu-abu. Itu disebabkan kandungan besi yang terdapat dalam tunjung dan adanya proses oksidasi membuat warna yang dihasilkan pada benang menjadi tua (Fardhyanti dan Ria, 2015).

Hal tersebut mendukung teori dari Titik, (2014) yang mengatakan bahwa proses fiksasi pada prinsipnya adalah mengkondisikan zat pewarna yang telah terserap dalam waktu tertentu agar terjadi reaksi antara bahan yang diwarnai dengan zat warna dan bahan yang digunakan untuk fiksasi. Fiksasi juga salah satu langkah pada proses perendaman yang bertujuan untuk mengunci dan membangkitkan zat warna.

\section{KESIMPULAN}

Berdasarkan hasil analisis data dan pembahasan dapat ditarik kesimpulan bahwa variasi waktu maserasi berpengaruh terhadap ekstrak zat warna dari daun sirih hijau (Piper Betle L.) dengan metode maserasi. Waktu optimum variasi maserasi untuk ekstraksi zat warna dari daun sirih hijau (Piper Betle L.) dengan metode maserasi adalah variasi waktu maserasi 2 jam yang menghasilkan nilai absorbansi 3,907. Variasi waktu maserasi berpengaruh terhadap hasil warna pada bahan baku benang tenunan.

\section{DAFTAR PUSTAKA}

Andjalita, Shabrina. (2015)."Pewarna Kain Mori Primissima Menggunakan Daun Sirih Hijau (Piper Batle L) Dengan Fiksator Jeruk Nipis, Gula Kelapa, Dan Kapur Tohor ". Abstrak-Skripsi. Malang: FT Jurusan Tata Busana.UM.(online).

Azizah, Wahidatun, N. (2018). Pengaruh Jenis Zat Fiksasi Terhadap Kualitas Pewarnaan Kain Mori Primissima dengan Zat Warna Euphorbia. Yogyakarta: Universitas Negeri Yogyakarta.

El-Nagar, K.,Sanad, S.H., Mohamed, A.S.,\& Ramadan, A. (2005). Mechanical Properties and Stability to Light Exposure for Dyed Egyptian Cotton Fabrics with Natural and SyntheticDyes.PolymerPlastics Technology and Engineering.

Fardyanti, D., S., \& Ria, D., R. (2015). Pemungutan Brazilin dari Kayu Secang (Caesalpinia Sappan L) dengan Metode Maserasi dan Aplikasinya untuk Pewarnaan Kain. Jurnal Bahan Alam Terbarukan, 4 (1):6-13.

Lestari, A. A., Evy, W., \& Yeni, M. (2018). Pemanfaatan Tumbuhan Penghasil Warna Alami Untuk Tenun Ikat Oleh Suku Dayak Iban Di Dusun Tekalong dan Dusun Kelawik Kapuas Hulu Kalimantan Barat. Jurnal Hutan Lestari, 6 (4):837-847

Mi'raj, Nurul. (2013). Perkembangan Tenun Bima. Skripsi (tidak diterbitkan).Jurusan Pendidikan Kesejahteraan Keluarga,UNDIKSHA Singaraja.

Ruslan dan Wiraningtyas, A. (2019). EKSTRAKSI ZAT WARNA DARI RUMPUT LAUT Sargassum sp. Jurnal Redoks: Jurnal Pendidikan Kimia Dan Ilmu Kimia, 2 (1), 1-10. 
Ruslan, R., \& Agustina, S. (2020). UJI KESTABILAN PENYIMPANAN EKSTRAK ZAT WARNA ALAMI DARI RUMPUT LAUT Sargassum sp. JURNAL REDOKS: JURNAL PENDIDIKAN KIMIA DAN ILMU KIMIA, 3(1), 1-7.

Septiandini, T. N., dan Muflihati. (2019). Ekstrak Buah Bakau Rhizophora mucronata Lamk Sebagai Pewarna Alami Pada Kain Katun. Jurnal Tengkawang, 9 (1): 1-13.

Sutara, P.K. (2009). Jenis Tumbuhan sebagai Pewarna Alam pada Beberapa Perusahaan Tenun di Gianyar. Jurnal Bumi Lestari.

Thomas, M., Manuntun, M., \& I. A. Raka, Astiti A. (2013). Pemanfaatan Zat Warna Alam dai Ekstrak Kulit Akar Mengkudu (Morinda citrifolia Linn) Pada Kain Katun. Jurnal Kimia, 7 (2): 119-126.

Titik Pujilestari. (2014). Pengaruh Ekstraksi Zat Warna Alam dan Fiksasi Terhadap Ketahanan Luntur Warna Pada Kain Batik Katun. Dinamika Kerajinan dan Batik , Vol.31, No.1

Uddin, M. G. (2015). Extraction of Eco Friendly Natural Dyes from Mango Leaves and Their Application on Silk Fabric.Textiles and Clothing Sustainability.

Wiraningtyas, A., Ruslan, Rohaeti, E., Budiasih, K. S., Mutmainnah, P. A., Agustina, S., Annafi, N., and Perkasa, M. (2020). Application of Natural Dyes and Sodium Alginate From Sargassum Sp. Sea weed In Coloring Bima Woven Fabric. Oriental Journal of Chemistry. Vol. 36 (5): $964-967$. 